Revista de la red interuniversitaria de estudios sobre las literaturas rioplatenses contemporáneas en Francia

$7 \mid 2012$

Arqueologías

\title{
Leer los comienzos. Orientaciones teóricas, Borges,
} Saer

Julio Premat

\section{OpenEdition}

\section{Journals}

Edición electrónica

URL: http://journals.openedition.org/lirico/594

DOI: $10.4000 /$ lirico. 594

ISSN: 2262-8339

Editor

Réseau interuniversitaire d'étude des littératures contemporaines du Río de la Plata

Referencia electrónica

Julio Premat, «Leer los comienzos. Orientaciones teóricas, Borges, Saer », Cuadernos LIRICO [En línea], 7 | 2012, Publicado el 11 octubre 2012, consultado el 22 septiembre 2020. URL : http:// journals.openedition.org/lirico/594 ; DOI : https://doi.org/10.4000/lirico.594

Este documento fue generado automáticamente el 22 septiembre 2020

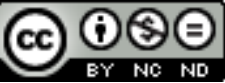

Cuadernos LIRICO está distribuido bajo una Licencia Creative Commons Atribución-NoComercialSinDerivar 4.0 Internacional. 


\title{
Leer los comienzos. Orientaciones teóricas, Borges, Saer
}

\author{
Julio Premat
}

Bajo el título Arqueologías. Archivos, borradores, genealogías de escritura, se pretendió reunir y cruzar posibles trabajos sobre crítica genética, sobre archivos de escritores, sobre los inicios de una producción literaria o de un texto en particular, sobre las narraciones variables que el autor y el campo literario construyen alrededor esos comienzos, sobre relatos legendarios del origen de las cosas. Durante dos años, en seminario o en jornadas de estudio, tuvimos la oportunidad de dialogar con investigadores de nacionalidades y orientaciones críticas diferentes. Este número de los Cuadernos LIRICO reúne una selección de textos de algunos de esos encuentros, así como testimonios y diálogos con escritores. El texto que sigue retoma el documento de orientación conceptual distribuido antes de la primera reunión y un resumen de la intervención sobre Juan José Saer que propuse para ilustrar ese breve panorama teórico. Se trata de una recuperación organizada, en función del tema propuesto, de líneas teóricas e interpretaciones críticas conocidas. Su objetivo era -es- el de abrir líneas de estudio posibles.

\section{Presentación}

2 El punto de partida intuitivo, si lo declinamos en preguntas sería : ¿cómo empieza un texto? En todos los sentidos: ¿dónde empieza la escritura de un texto? ¿Cuál es su inicio o su punto de surgimiento -qué se puede saber o decir sobre el tema-? ¿Cómo se construye un corpus coherente? ¿A partir de qué criterios, convenciones y posiciones? ¿Qué implica un primer libro, una primera frase, un primer texto en una compilación ? Por lo tanto, y más allá, ¿cómo se vuelve alguien escritor? ¿Qué implica publicar -o no hacerlo-? ¿Cómo leer, en contraluz, todo lo que rodea a lo publicado y lo público (los otros textos, los borradores, las periferias de la"obra")? ¿Qué lugar atribuirle a los papeles dejados por un escritor? ¿Qué relaciones se traman así con lo ya escrito, con la tradición, con la cultura? Y, una vez ese comienzo realizado (del texto, del conjunto de 
un corpus denominado obra), ¿cómo estudiar ese proceso? ¿Dónde está la primera página, cuáles son las causas, cuáles los efectos ? ¿Cómo funciona la idea del"origen" en cualquier relato sobre el tema? ¿Cómo los escritores cuentan esa historia, qué funciones tendrían esos relatos? ¿Cómo y partir de qué postulados la crítica literaria construye también relatos sobre ese"origen" ?

Para estructurar análisis que problematicen esas preguntas, la idea fue la de recurrir a términos que puedan ser tanto conceptos como imágenes. El título"arqueologías", sin ser un concepto en el sentido estricto, pretende, con su referencia a Foucault, ir más allá de la respuesta llana a las preguntas precedentes. Es decir, pretende interrogar intrínsecamente el concepto de historia lineal de producción de un texto o de un corpus, abrir la idea de obra que es inherente a la posibilidad de narrar una historia en el sentido de revelación de causas, consecuencias e intenciones, cuestionar la existencia de un origen en tanto que punto absoluto, anterior al texto, que podría identificarse como grado cero, esencial y determinante de todo lo que vendrá, e inclusive repensar el objeto en sí de archivo, que, como es sabido, tiene una etimología en común con arqueología (el arché).

Para ilustrar lo que precede, una enumeración no limitativa de temas imaginables :

- Estudiar la"entrada en escritura" : primeros textos, primeras publicaciones, estrategias y efectos.

- Estudios genéticos : variantes, manuscritos, correcciones entre diferentes ediciones. Modos de preparación y"disparadores" de escritura.

- Relatos de origen incluidos en los textos : representaciones imaginarias de un comienzo.

- Relatos autobiográficos y autoficcionales sobre el origen de la escritura.

- Filiaciones literarias, construidas por el autor o por la crítica.

- Incipits de los textos : primeras líneas de un relato, primeros versos, modos de marcar la irrupción del propio discurso.

- Organización y reorganización de ediciones (antologías, recopilaciones, etc.) ; efecto del orden, paratextos, títulos, etc.

\section{Orientaciones teóricas}

5 En los párrafos que siguen crucé y desarrollé algunas lecturas bibliográficas para comenzar una delimitación conceptual. Hay que reconocer que, en buena medida, las afirmaciones no son más que una serie de negaciones o, digamos, que un protocolo negativo (lo que no es una historia, un origen, una obra, etc.) ; protocolo negativo que, en algunas articulaciones, se opone al tipo de análisis que se puede llevar a cabo sobre génesis, posición el sujeto creador o inscripción de una entrada en la literatura en una filiación o en una tradición. Pienso, con todo, que para el comienzo de un proyecto (recuérdese que el gesto inaugural forma parte de lo que nos proponemos estudiar), no es superfluo problematizar los posibles acercamientos a fenómenos particulares, como para abrir perspectivas de estudio que no sean, al menos, ingenuas.

6 Algunas dicotomías y series conceptuales podrían abrir perspectivas de estudio a partir de una problematización, de tradición tanto crítica como epistemológica :

- arqueología/historia

- origen/genealogía

- obra/borrador

- publicación/inédito/archivo 
- comienzos/proyecto

\section{1) Historia/Arqueología}

7 Retomando la presentación introductoria, la primera pregunta sería ¿cómo narrar la procedencia y el surgimiento de un texto -de la literatura-? ¿Cómo empezar y organizar ese relato? ¿Qué implica, en sí, una"historia" ?

De cara a las operaciones que supone esa narración, en tanto que construcción de sentidos, podemos seguir el análisis sintético que Agamben ("Archéologie philosophique") hace del tema en un plano epistemológico (o sea : ver en la"historia" de una"obra" la posibilidad en general de toda historia del saber, en particular de una historia de la razón o de la filosofía). Para empezar, Agamben alude a posiciones de Kant, que afirma que una historia filosófica de la filosofía sólo puede tomar la forma de una arqueología, es decir tanto una ciencia de las ruinas, del análisis de los restos del pasado sobre los cuales construir la propia filosofía, como una historia de lo no sucedido :"L'histoire de la philosophie est d'une espèce si particulière qu'en elle on ne peut raconter rien de ce qui est arrivé, sans connaître d'abord ce qui aurait dû ou pu arriver". ${ }^{1}$ Por lo tanto, también, la historia de las cosas sin comienzo, una historia de las eventualidades.

Pero, por supuesto, el término de"arqueología" está ante todo asociado a Foucault (y a su libro L'archéologie du savoir), en tanto que opción frente a un saber construido como una historia. En el comienzo de ese libro, Foucault se propone llevar a cabo un trabajo negativo : liberarse de una serie de nociones que remiten, de una manera u otra, a una continuidad, es decir que asocian todo surgimiento de discurso a fenómenos precedentes, instaurando una serie causal y determinante (a saber: la tradición, la influencia, el desarrollo y la evolución, la mentalidad); también problematiza y toma distancia de elementos que instauran una unidad forzada : género, libro, obra, sujeto creador. ${ }^{2}$ Disipar este tipo de elementos tiende a redefinir la manera de estudiar los fenómenos discursivos, en particular rompiendo la obligación de encontrar transiciones entre unos y otros - de construir un relato-. Al respecto, una cita de ese libro y otra de Agamben comentado sus posiciones :

Disons pour faire bref que l'histoire, dans sa forme traditionnelle, entreprenait de"mémoriser" les monuments du passé, de les transformer en documents et de faire parler ces traces qui, par elles-mêmes, souvent ne sont point verbales, ou disent en silence autre chose que ce qu'elles disent; de nos jours, l'histoire, c'est ce qui transforme les documents en monuments, et qui, là où on déchiffrait des traces laissées par les hommes, là où l'on essayait de reconnaitre en creux ce qu'ils avaient été, déploie une masse d'éléments qu'il s'agit d'isoler, de grouper, de rendre pertinents, de mettre en relation, de constituer en ensembles. Il était un temps où l'archéologie, comme discipline des monuments muets, des traces inertes, des objets sans contexte et des choses laissées par le passé, tendait à l'histoire et ne prenait sens que par la restitution d'un discours historique ; on pourrait dire, en jouant un peu sur les mots, que l'histoire, de nos jours, tend à l'archéologie -à la description intrinsèque du monument. ${ }^{3}$

Nous pouvons appeler provisoirement"archéologie" cette pratique qui, dans toute enquête historique, n'a pas affaire à l'origine, mais au point de surgissement $d u$ phénomène et doit par suite aborder de manière nouvelle les sources et la tradition. Elle ne peut se mesurer avec la tradition sans déconstruire les paradigmes, les techniques et les pratiques par lesquels elle règle les formes de la transmission, conditionne l'accès aux sources et détermine, en dernière analyse, le statut même 
$\mathrm{du}$ sujet connaissant. Le point de surgissement est donc ici à la fois objectif et subjectif et se situe plutôt dans un seuil d'indécidabilité entre l'objet et le sujet. Il ne fait jamais apparaître le fait sans faire apparaître en même temps le sujet connaissant lui-même : l'opération sur l'objet est en même temps, une opération sur le sujet. ${ }^{4}$

10 ¿Lo que precede justifica la denominación de"Arqueología" para el tipo de trabajo hecho en nuestro seminario? Por supuesto que, si partimos de una idea de rigor conceptual (y/o de la existencia viable de semejante"arqueología del saber"), la respuesta sería no. Pero me parece que desarticular las certezas de una"historia" y tomar conciencia de las operaciones del crítico, aun cuando estemos construyendo un relato, es un gesto interesante. Por otro lado, el trabajo con"evidencias" (como se denominan los signos, necesariamente herméticos, que los arqueólogos encuentran en sus excavaciones), llevando a cabo asociaciones lógicas que intenten explicar algo para siempre inasible (modos de vida, creencias, historia de una sociedad desaparecida, a veces hace miles de años), no deja de ser una metáfora modesta y fértil para un estudio de borradores, surgimiento, comienzos de textos: no contar una verdad sino asociar las"evidencias" que quedan de un proceso enigmático.

\section{2) Origen/Genealogía}

11 Aunque genética, la visión del origen no sería entonces la de una simple historia de escritura : no se trata de utilizar los documentos como modo de reconstituir el pasado o una verdad del pasado para explicar un fenómeno, sino de analizarlos en tanto que materia en sí. Foucault, de nuevo, comentando las posiciones de Nietzsche sobre el origen, afirma:"La généalogie ne s'oppose pas à l'histoire comme la vue altière et profonde du philosophe au regard de taupe du savant; elle s'oppose au contraire au déploiement métahistorique des significations idéales et des indéfinies téléologies. Elle s'oppose à la recherche de 'origine'". ${ }^{5}$

Consecuentemente, el rechazo de la idea de origen tendría para él tres justificaciones.

Primero, el origen supondría una esencia exacta de la cosa, su posibilidad más pura, su identidad cuidadosamente dirigida hacia sí misma, su forma inmóvil y anterior a todo lo externo, accidental y sucesivo. Buscar el origen no sería, entonces, más que buscar lo que ya está, postulando una identidad primera. Sin embargo, continúa Foucault, el problema sería que detrás de las cosas hay"otra cosa" : no un secreto esencial y sin fecha, sino el secreto de que las cosas no tienen esencia, o que su esencia fue construida a partir de figuras ajenas a ella.

14 Luego, el origen supondría una solemnidad, según la idea de que, en el comienzo de las cosas se encuentra lo más esencial y lo más valioso. La perfección estaría en el origen, en el momento en que las cosas surgieron de las manos del creador durante la primera mañana. El origen, por lo tanto estaría imaginariamente situado siempre antes de la caída, antes del cuerpo, antes del mundo y el tiempo : el origen estaría del lado de los dioses. Pero, recuerda Foucault citando a Nietzsche, el comienzo histórico es en realidad bajo, irrisorio, irónico : detrás del origen del hombre, para empezar, no hay un nacimiento divino sino un mono.

15 Tercer postulado: el origen sería el lugar de una verdad, anterior a cualquier conocimiento. El origen sería el punto, perdido para siempre, en que la verdad de las cosas se articularía con el discurso sobre las cosas, sin pliegues, sin sombras ni 
disociaciones. De nuevo, habría que dar vuelta la creencia:"...derrière la vérité, toujours récente, avare et mesurée, il y a la prolifération millénaire des erreurs. [...] La vérité, sorte d'erreur qui a pour elle de ne pouvoir être réfutée, sans doute parce que la longue cuisson de l'histoire l'a rendue intaltérable." ${ }^{16}$

Por lo tanto, la visión del origen debe ser, más que matizada, pensada como una construcción lógica e imaginaria, perceptible a partir de un resultado. El origen será una ficción, un relato, que en resonancia o en consonancia con la obra, desarrolla líneas de sentido, mientras que el término genealogía permite preservar una especificidad mayor para cada acontecimiento, sin ordenarlos en una serie de lógicas determinadas por el origen (y de hecho, determinantes en toda la serie). El término genealogía tiene otras ventajas, más inmediatas : primero, la de abrir las causas de un fenómeno hacia una multitud de causas (en la analogía genealógica : a la pluralidad de antepasados), que ocupan un nivel o función equivalente. Segundo, la de asociar el surgimiento de un texto a una serie cultural (a un linaje), vale decir a un modo de situarse en una tradición que parte, también, de una pluralidad."Linaje" que cabría leer, de nuevo, como la organización de una arbitrariedad de hechos y una multiplicidad de sujetos en una figura coherente.

\section{3) Obra/Borrador}

La puesta en duda y en escena de un relato de origen, implica, claro está, interrogar el concepto de obra, concepto simétrico al de autor en nuestra cultura (vale decir, uno de esos conceptos ampliamente discutidos y criticados pero que sin embargo siguen siendo operativos). La obra supone un conjunto cerrado, terminado, significativo, económicamente suficiente (en ese sentido dialoga con la idea de autor : la"intención" de uno es la imagen simétrica del"equilibrio" y la"exhaustividad" de la otra). La obra será entonces una figura activa en la circulación de la literatura e, inclusive, una condición de posibilidad en la construcción de sentidos y valores de una cultura.

Puede verse una obra como un valor atribuido a un conjunto de textos; según Louis Hay, una obra es, tradicionalmente, una producción estética coherente y terminada, individual y autónoma. ${ }^{7}$ Falta de contradicciones internas que suponen un proyecto, una intención y una lógica ("coherente"), un cierre que determina y fija sus valores ("terminada"), inherente a la presencia previa y paralela de un sujeto responsable que produce el conjunto y al que esa producción pertenece ("individual"), y capaz de funcionar en el campo literario como una entidad aparte, identificable tanto por una esencia propia como por ser económicamente suficiente ("autónoma").

o sea que"obra" sería en cierta medida un concepto que supera el conjunto de partes que la constituyen; o, siguiendo a Jean-Claude Milner, la obra sería una"forma". Efectivamente, en sus reflexiones sobre la"obra" de Lacan, constituida a la vez por textos"escritos", por seminarios publicados y/o por seminarios todavía inéditos, Milner empieza definiendo así la noción de obra :

La notion d'œuvre est moderne. Si du moins on la prend en un sens strict, comme ce principe d'unicité qui permet d'introduire dans le multiple de la culture un décompte et des différenciations. Cette unicité est centrée autour d'un système de nominations -les noms de l'auteur et le titre de l'œuvre-, subsumant des productions matérielles, en particulier du texte, sous le régime de l'Un. La question de savoir s'il y a un ou plusieurs textes est au reste tout à fait secondaire, puisque c'est la nomination qui les constitue en Un: autrement dit, l'œuvre n'est pas 
nécessairement un livre, ni même nécessairement un livre. L'œuvre n'est pas une matière, c'est une forme et c'est une forme qui organise la culture. ${ }^{8}$ organizar una cultura (y, decíamos, de permitir la circulación de los textos). Esa organización puede tomar la forma, claro está, de un relato (con sus consabidas marcas de comienzo-origen y cierre-remate lógico)

21 La idea de cierre, inherente a la obra, se ve así fisurada por lo inacabado, lo abierto, lo que no tiene una forma definida o rígida. En un primer momento, puede verse lo inacabado como el resultado de accidentes en el proceso productivo (los célebres esclavos de Miguel Ángel, la octava sinfonía de Schubert o buena parte de los relatos de Kafka). Pero este último ejemplo, a pesar de la abrumadora mitología autoral que rodea y explica el fenómeno (desde la carta al padre a la traición póstuma del amigo que publica en vez de destruir esos borradores destinados a ser, espléndida paradoja, una gran"obra"), apunta a un fenómeno inédito del siglo XX, que acompaña en parte la emergencia de las vanguardias : la puesta en duda de la obra en tanto que conjunto cerrado, pleno, saturado de sentido. Así, de lo inacabado como accidente pasaríamos a una afirmación de lo inacabado (a la"obra abierta" se dijo en un momento dado de la historia de la crítica) ; y, más allá, a una estética de lo inacabado, como pudo haber una estética de las ruinas en los jardines de fines del siglo XVIII. Lo inacabado como una posición, un postulado y una concepción de la forma : como otra concepción, que valdría la pena interrogar al pensar en lo que llamamos obra en la literatura del último siglo. En particular a la hora de pensar en los márgenes : Milner recuerda la definición de la locura dada por Foucault :"la folie comme absence d'œuvre". ${ }^{9}$

Lo que antecede viene a cuenta de la irrupción en el campo de la crítica de los estudios de manuscritos, borradores y materiales prerredaccionales, desde una posición más matizada que la filología tradicional. Efectivamente, otra de las aperturas posibles de la Obra, simétrica, es la perspectiva genética que se ha desarrollado en los últimos veinte o treinta años : los textos dejan de aparecer como un absoluto desprovisto de capas y de rugosidades, para convertirse en el efecto de un proceso (el que el trabajo genético permite recorrer). Por lo tanto, la idea de Borrador podrá compensar de manera activa el absolutismo de la de Obra y funcionar en el estudio de etapas lógicas y fronteras de formación del corpus de un autor.

Lo que precede (puesta en duda de la"obra", valor de lo inacabado y de la noción de"borrador", perspectiva genética que abre el texto a capas anteriores), puede llevar a leer de otra manera, afirma Louis Hay. ${ }^{10}$ Leer, no a partir de un resultado, dado al lector como inicio de un proceso de significación, ni menos todavía como recepción pasiva de intenciones, efectos y sentidos predeterminados para siempre, sino leer a partir del proceso de escritura, leer el resultado como una etapa en un hacer, desplegando las capas geológicas de lo que precede, lo que explica, lo que actúa en el texto leído. El arte del siglo XX iría progresivamente concentrándose, entonces, en ese hacer en vez de en lo que está ya hecho. Louis Hay cita a Mallarmé anunciando la necesidad de escrutar el origen del acto de escribir, a Gide dedicándole un libro al hecho de escribir (1895), a Proust escribiendo una novela entera en busca de la escritura, a Valéry afirmando"le faire comme principal et telle chose faite comme accessoire, voilà mon idée". Y pone de relieve la curiosidad que suscita el proceso de escritura :"il peut arriver que l'on soit entraîné à considérer avec plus de complaisance et même plus de passion, l'action qui fait que la chose faite". 

paso del borrador al texto publicado, de leer lo inédito (y/o de darlo a leer) y de preservarlo. Muchos fenómenos literarios, muchas figuras de escritor, muchas obras, han sido duraderamente transformadas por ciertas modalidades de edición (en particular, de edición póstuma) y por ciertos procesos de sacralización (o de institucionalización) de lo inédito. sobre un proceso que, en última instancia, es misterioso para el propio escritor. El relato genético construiría procesos, que pueden permitir pensar la literatura en general y las condiciones de posibilidad de un ejemplo dado, sin funcionar alrededor de un concepto de verdad (remitiéndonos a la idea de la ficción como instancia ni cierta ni falsa, pero como lugar de resolución de las contradicciones de lo real).

Por lo tanto, en las últimas décadas tendemos a no ver más o no ver sólo a la literatura en el libro publicado, en el texto sacralizado, sino en el proceso que le dio lugar, en el espesor temporal y en los titubeos que llevaron a él. Tomar la obra como borrador será insertarla en una genealogía múltiple.

\section{4) Publicación/Inéditos/Archivos}

Origen y Obra suponen, ambos, una publicación (en todos sus sentidos : una edición, una circulación pública, aceptada y aceptable, de ciertos textos). Desde ya, podremos interrogarnos sobre el sentido del acto de publicar (la poubellication decía Lacan ${ }^{11}$ ), vale decir sobre el valor estético y social de la publicación (interrogar, es decir : desmontar evidencia del gesto, marcando el proceso y sus consecuencias). ¿Cómo se construyen los libros misceláneos, las compilaciones, las antologías? ¿Qué sucede con las publicaciones póstumas, la publicación de inéditos, de borradores o de textos"no literarios" ?

Evidentemente la publicación pone de relieve, en negativo, lo no publicado, lo impublicable (lo"impúblico" le oí decir a Dardo Scavino) : ¿qué lugar ocupa lo inédito frente a lo editado ? ¿Cómo publicar póstumamente? ¿Qué transformaciones supone la publicación ? ¿Cómo se desplaza la visión de una producción y la coherencia de un autor al publicar borradores y textos marginales?

El"cómo publicar" supone, por lo tanto,"cómo leer" o"cómo dar a leer". La existencia de lo inédito o de lo impúblico frente a lo publicado lleva a un tercer término, el de archivos. ¿Cómo organizar, preservar y transmitir el conjunto de papeles y documentos de y sobre un escritor? ¿Qué postulados y efectos esa preservación organizada presupone ? Una cita sobre los archivos, que pone de relieve el valor de autoridad o de institucionalización que adquiere el sistema de organización de un archivo (cita previsible : la apertura -el comienzo- del libro de Derrida sobre el tema, Mal d'Archive) :

Ne commençons pas au commencement, ni même à l'archive.

Mais au mot"archive" -et par l'archive d'un mot si familier. Arkhé, rappelons-nous, nomme à la fois le commencement et le commandement. Ce nom coordonne apparemment deux principes en un : le principe selon la nature ou l'histoire, là où les choses commencent -principe physique, historique ou ontologique-, mais aussi le principe selon la loi, là où des hommes et des dieux commandent, là où s'exerce l'autorité, l'ordre social, en ce lieu depuis lequel l'ordre est donné -principe nomologique. ${ }^{12}$

Todo lo dicho anteriormente en estas notas se cristalizaría en los modos de pensar el institucionalización) de lo inédito. 


\section{5) Principios/Proyecto} Said sobre los comienzos (o principios, o inicios) ; lo que él denomina los beginnings (y en el inicio de su libro encontramos una exposición autorreflexiva sobre su propia problemática : cómo comenzar un libro sobre los comienzos). Comenzar determina lo que sigue, construye la principal entrada en lo que se leerá, establece relaciones de continuidad y antagonismo con lo escrito antes. Y, más allá, Said postula que comenzar es el primer paso en la producción intencional de sentido. ${ }^{13}$ Ampliando estas ideas, encontramos las determinaciones de una"entrada en literatura" como modo de situar y de poner en resonancia una producción en un campo literario y ante una biblioteca heredada. su comienzo. O sea, determinado por los primeros gestos (los primeros textos, las primeras ediciones, las primeras intervenciones en el campo literario). El proyecto puede pensarse entonces desde una posición tradicional (la del escritor demiurgo que desarrolla a partir de cero un proyecto preestablecido) o desde lo dicho sobre el origen y la obra : el proyecto como una forma que se define a medida que se desarrolla, a la vez causa y consecuencia de lo escrito. Dicho de manera más paradójica: el proyecto, en tanto que materialización de una intención y que estructura de coherencia, es un efecto retrospectivo (no hay comienzo sin continuación y por lo tanto el sentido del comienzo y sus efectos sólo se materializan en el después).

Al respecto se puede comentar (lo propuso alguna vez Diego Vecchio) el proyecto por antonomasia de la literatura europea, el de Balzac. Porque es interesante recordar algunas observaciones que hace Proust en La prisionera, el quinto volumen de En busca del tiempo perdido, sobre un nuevo tipo de obra de arte que nace con Balzac (y entendemos que Proust piensa también en su propio proyecto entonces). Según Proust, la idea de reunir a todas sus novelas en una sola, intitulada La Comedia Humana, gracias a la reaparición de los mismos personajes, fue un hallazgo de último momento. A la inversa de la idea de escritores postulando un programa como punto de partida, en Balzac el proyecto resultó ser más bien un punto de llegada. La obra balzaciana no fue la aplicación mecánica y rígida de un programa definido de antemano, sino el descubrimiento de una unidad que hasta el momento se ignoraba : la totalidad no fue una causa sino un efecto. La obra de Balzac no es ni totalidad orgánica ni totalidad teleológica sino una totalidad que surge de las partes, como una parte más.

De manera más restringida y precisa, el paso de la página en blanco a la primera frase (el inicio de una escritura), en el plano genético, o el estudio de los incipits de las versiones definitivas, son un lugar de observación fértil, tanto sobre una concepción del origen, de la literatura y del proyecto, como sobre la relación con la recepción, las determinaciones de sentido $\mathrm{y}$, si se quiere, como un condensado minúsculo del proyecto. El dominio de lo narrado o los inicios paradójicos, la afirmación o la duda, la manera de recuperar o de contradecir una tradición al respecto, los juegos de saber e ignorancia, las resonancias intertextuales : todo esto puede observarse en, a veces, una o dos frases inaugurales. Valga el aforismo: en los incipits puede estudiarse, también, toda la literatura. 


\section{Borges y Saer : las paradojas del comienzo}

34 Para prolongar y darle mayor claridad a estas rápidas notas inaugurales, no es quizás inútil evocar el ejemplo de Borges, que por supuesto es modélico en la revisión de las concepciones tradicionales de la literatura en nuestro campo de investigación, revisión que no sólo problematiza y discute, sino también prolonga y retoma, de manera paradójica. Y, luego, propongo desarrollar el caso Saer, que puede considerarse prolonga una visión contradictoria del comienzo y permite ilustrar las múltiples connotaciones del tema propuesto.

\section{1) Borges. Comenzar lo ya escrito}

Es una banalidad señalar que las prácticas literarias de Borges, y las concepciones que las sostienen, se caracterizan por una fuerte tensión lógica. Por un lado, y es otro lugar común recordarlo, Borges es el escritor de la reescritura, de la repetición, de la novedad o de la originalidad fuera de alcance, del eterno retorno de lo mismo, de una creación que se inscribe en algo ya comenzado y en un juego de reflejos sin fin, y, por último, en una exaltación de la lectura en vez de la invención"absoluta". o sea, aparentemente, en los antípodas de la fundación, la originalidad, la"primera vez" reivindicada por la tradición romántica o por las vanguardias. Si no vale la pena desarrollar esta vertiente de su producción, podríamos contraponerle una serie de puntos en los cuales, y a pesar de la incrédula lucidez, muestran a un Borges sacando provecho estético de una ficción de origen, poniendo en escena comienzos fabulosos o determinantes, jugando con los efectos de lo inaugural o de lo singular.

Una enumeración heterogénea, que podrá ser tomada como una lista de posibilidades de análisis :

- Biografías. Tanto en el plan personal (la autobiografía) como en la de múltiples personajes, históricos o ficticios, para el esquema fundamental de toda narración parece ser, en muchos casos, el del relato biográfico, en particular en lo que atañe a las determinaciones de los orígenes y de las experiencias de los primeros tiempos. Desde su entrada en la ficción, materializada por biografías imaginarias (la de Evaristo Carriego, las de Historia universal de la infamia), a las muy frecuentes vidas narradas a lo largo de su obra, pasando, por supuesto, por las puestas en escena, obsesivas y sistemáticas, de su historia familiar y del conflicto de linajes que la caracterizaría. Este relato mitifica, más o menos irónicamente, el pasado personal (linaje, infancia), en tanto que explicación del devenir del sujeto.

- Orígenes de la obra. Sea en el plano histórico (su entrada en literatura con textos vanguardistas denostados o polémicos ensayos) o legendaria (el origen mil y una vez fabulado de los textos escritos), Borges va a desplegar versiones contradictorias y construidas sobre esos comienzos. Por un lado, con gestos de disimulación y deformación de sus primeros pasos en la literatura (la reescritura sistemática de su pasado literario) o la mitificación de ciertos lugares y ciertas prácticas, en tanto que fundadores y fundamentos del acto de escribir (la biblioteca, la lectura).

- Ediciones. Los libros de Borges, ya se sabe, nunca son definitivos : la edición y la reedición son espacios que permiten transformaciones permanentes, por ejemplo en el orden de los textos o en la inclusión, progresiva y sistemática de prólogos, liminares y demás textos inaugurales que transforman y prolongan la lectura de textos ya publicados. Como pocos 
otros autores, Borges vuelve una y otra vez al"comenzar" de sus libros y su obra, modificando las entradas, los preliminares, los textos que orientan y transforman la lectura.

- Incipits. Las primeras frases de los textos de Borges confirman, de manera hiperbólica, las afirmaciones que postulan que el incipit establece una red de intercambios con la tradición literaria y supone una serie de tomas de posición estéticas, lógicas e inclusive metafísicas. Cada vez, para Borges, empezar un texto es hacer un gesto específico de entrada en la cultura a partir de una posición reconocible, una voz y un tono propios. Casi siempre virtuosos en su polisemia y superposición ambigua de universos referenciales, en esos incipits se juega buena parte de su literatura.

- Fundaciones. La obra de Borges se caracteriza por una invención recurrente de mundos, de libros exhaustivos, de países fabulosos, de objetos hiperbólicos que abarcan la totalidad de lo existente. La discreta megalomanía borgeana lo convierte en un equivalente del primer demiurgo, Dios, inventor de todo (en ese sentido cabe leer el título de uno de sus libros principales, El hacedor). Desde la incredulidad, se reinventa el cosmos : que su primer libro de cuentos, El jardín de los senderos que se bifurcan, comience por la creación de un universo aparte, cifra de toda la obra, es un signo explícito de este programa fundador.

- Intertextos. En la serie de textos citados e incorporados por Borges en su obra, se puede establecer categorías recurrentes y una tipología más o menos coherente. Una de las categorías más visibles es la utilización de textos considerados, de una manera u otra, como fundadores. Borges no sólo cita o reescribe, sino que muchas veces citas y reescrituras retoman libros del inicio, esas primeras páginas consideradas como inaugurales por una cultura en algún momento : mitología griega o escandinava, La Biblia, La Divina Comedia, Don Quijote, Martín Fierro, etc. La obra dialoga a menudo con lo que se convierte, desde Borges, en un género, es decir el texto de los inicios, estableciendo así improbables parentescos entre libros disímiles.

Valga esta apretada enumeración en tanto que ilustración de algunas orientaciones posibles de reflexión (a las que habría que agregarle, claro está, el proceso de escritura de Borges en términos genéticos, campo de estudio relativamente virgen que Daniel Balderston empieza a recorrer). Por el momento, podríamos evocar otro ejemplo, borgeano a su manera (pero también onettiano o faulkneriano), el de Saer.

\section{2) Saer : inventar lo existente}

La producción de Saer gira alrededor de una problematización del origen : cómo empezar, qué decir para empezar, qué quiere decir empezar, cuál es el lugar para empezar y cómo, en qué, por qué, ese comienzo prepara y permite la escritura posterior. Del origen en tanto que determinación imaginaria del porvenir, encrucijada para postular una literatura todavía concebible, lugar de interrogantes sobre el sentido. Así, la conciencia metaliteraria y la representación recurrente de la escritura en sí misma, que tiene una larga tradición en el siglo XX y en la cual Saer se inscribe con vehemencia, se focaliza en este caso en la idea del principio, del principio en tanto que uno de los ejes de la peculiar construcción del corpus narrativo del escritor: el conjunto de sus relatos, dinámico e inestable, lleva repetidamente a preguntarse, de manera retrospectiva, sobre el origen. Los textos van así creando una idea y un espacio fuerte de origen, en sus dos sentidos más usuales : origen como lugar y origen como primer momento, instante de aparición, surgimiento -del mundo y de la palabra-. La pregunta del origen es, ya se sabe, la de la originalidad : el de dónde viene y el por qué empezar, incluyen la primera vez, lo nunca visto, y cierta posición ante la tradición. 
Pensar el comienzo es pensar el origen (de la obra, de la literatura, del sujeto), y por lo tanto es formular una hipótesis sobre la literatura y sobre la eventualidad, aún hoy, de escribir una gran obra novelesca -la eventualidad de seguir siendo original-.

En su obra encontramos una puesta en escena estructural y temática del principio, desplegado, negado, problematizado, transformado en origen legendario, en pertenencia, en imposibilidad; un principio fuertemente paradójico -cuando no oximorónico, según el modelo lógico heredado de Macedonio y de Borges-: se representa constantemente un origen y se presupone, al mismo tiempo, que todo ya estaba cuando emerge la propia escritura; se significa a cada paso la emergencia de un mundo y de una palabra, pero la mirada es retrospectiva y dubitativa; se narra una fundación pero siempre a posteriori, cuando el mundo, desprendido de ese origen absoluto, ya existe y funciona. Y también encontramos, como es lógico, una recurrente dramatización y representación paradójica del final; no es una sorpresa: no hay principio sin fin ni génesis sin teleología. Las ideas de comienzo y de origen, exasperadas, ocupan el lugar que ocupa la biblioteca en el proyecto borgeano : son una fuente de infinitas variaciones que, a partir de una negatividad, aseguran la existencia de una voz propia. $O$, si se quiere, una de las maneras de pensar el proyecto saeriano y las particularidades de construcción de su obra narrativa, es desplegar los valores y funciones que cobra ese eterno empezar. Cómo empezar, por dónde empezar, cuál es la primera página de la serie, repito, son preguntas centrales en Saer porque delimitan cierta apuesta metatextual que eludiría las aporías de una originalidad fuera de alcance poniendo en escena el proceso dubitativo de la propia escritura, de su emergencia, de la lógica de su expansión, de su progresiva viabilidad y visibilidad. Son singulares porque se convierten en el eje a la vez de las modalidades de construcción de los libros que giran alrededor de los espejeos de un comienzo y del conjunto que los incluye, así como dan lugar a una recurrente tematización de fundaciones, inicios cósmicos, espacios arcaicos, magmas primordiales.

En paralelo a la realizada sobre Borges, una enumeración rápida de niveles y de ejemplos como para precisar lo dicho y señalar así las perspectivas de investigación abiertas por estos interrogantes.

El comenzar, el origen, la fundación intervienen constantemente como polos productivos. Por lo pronto, pueden ser gestos editoriales. En 1960, la obra empieza con una compilación de cuentos, En la zona, libro que organiza, delimita y presenta lo ya escrito dentro de una forma específica. El inicio literario de Saer va a consistir en retomar textos ya escritos y a veces ya publicados, ordenarlos de manera significativa, presentarlos con un prólogo que anuncia una intención y proyecto que van mucho más allá de libro que los lectores podían leer en ese momento $\mathrm{y}$, al conjunto, darle un título que funciona como un acto de fundación, En la zona : zona en vez de Santa Fe, situación espacial ("en") como gesto de comienzo. Se empieza con el título y con la recuperación de lo ya escrito. Retrospectivamente, estos textos parecen contener, in nuce, toda la obra; sin embargo, de lo que se trata más bien es de un mecanismo: en su primera peripecia, la obra marca una norma (el anonimato de Santa Fe y el valor central de la localización) y un modo de funcionamiento (escribir, es decir empezar, crear, inventar, será retomar y reorganizar, por amplificación, variación y repetición, lo ya escrito). Como es sabido, uno de los mecanismos que primero se instala en el sistema de funcionamiento y engendramiento de la obra es la de presuponer y significar que todo lo que se escribe no es algo"nuevo" (no es"original"), sino que se trata de una 
reescritura y amplificación de algo que ya estaba escrito en alguna página anterior del propio Saer. Así, el origen -el auto-origen- niega la originalidad de lo que sigue -todo ya estaba- y, al mismo tiempo, este"auto-origen" asegura, en última instancia, una dimensión de originalidad. ${ }^{14}$

Estas coordenadas perduran en el funcionamiento del corpus saeriano, como una traza mnemónica leve pero determinante. En una enumeración rápida y heterogénea, destaquemos la conceptualización de cada relato publicado como un segmento inestable, inacabado, y por lo tanto la definición de toda la obra como el borrador de una perfección fuera de alcance (todo relato empezó antes pero ese comienzo no"termina", se prolonga sin desembocar en un relato pleno). En la serie, también podemos recordar que numerosas articulaciones del conjunto parecen replantear sus condiciones de posibilidad y situarse como una nueva página cero (o como una nueva fábula de una página cero). Por ejemplo, desde la última novela, La grande, que funciona como otra fundación, otro recorrido generalizante de todo lo escrito, $u$ otros muchos textos que retoman lo hecho, postulando una revisión aparente de sus principios y un inicio hacia otros textos (así podemos leer, por ejemplo, Cicatrices 1969, La mayor 1976, o Lugar 2000). Por otro lado, no es casual, en esta perspectiva, la presencia recurrente de una estructura circular de ciertos relatos organizados en secuencias, que vuelven, una y otra vez, a empezar lo narrado como El limonero real (1974) o Nadie nada nunca (1980).

Temáticamente, la producción saeriana es siempre autorreferencial, ya que también narra el propio surgimiento de los textos y, lógicamente, el surgimiento de la zona : el relato y el espacio son las dos caras de la misma emergencia. O sea, narra a la vez las condiciones que permiten la escritura y las circunstancias de una génesis (de un Génesis) de ese lugar que es indisociable a la obra. En algunas opciones se trata de un verdadero relato, el relato de origen de la zona que, reiterado, impregna al conjunto con una tonalidad de eterno comienzo. Se trata de una ficción mítica o legendaria : el momento de aparición de la palabra, gracias a una regresión, un despojamiento, un hundimiento en lo anterior y lo informe ; o, en sus versiones más complejas, una ficción que lleva a remontar hasta tiempos fuera del tiempo y, desde el barro primero y la página en blanco, ver surgir, en esa nada, un cosmos íntimo, el propio mundo narrativo (algo similar sucedía en Onetti : piénsese en La vida breve y la invención de Santa María). Por lo tanto, no sólo se realizan ciertas operaciones alrededor del comienzo sino que la idea en sí de comienzo, transformada legendariamente en origen, sigue interviniendo y suscitando ficciones a lo largo de cuarenta y cinco años de actividad creadora.

Una y otra vez, los relatos de Saer vuelven entonces a una especie de grado cero $u$ hora primera. Se trata de una repetida representación arcaizante de la escritura: la obra pone en escena la pérdida de todo saber, toda cronología, toda determinación cultural, para retroceder hasta un tiempo fuera del tiempo, a un instante mágico, involuntario y sufriente, a una dimensión en la cual la tradición, ausente, se encuentra reemplazada por la pulsión : sólo entonces se logra pasar de la nada a la primera palabra. Es lo que sucede en El limonero real, novela organizada alrededor de una puesta en escena exasperada del comienzo. En su estructura ante todo. El texto se abre con un dístico evocador :"Amanece / y ya está con los ojos abiertos", inicio (el amanecer), en el cual algo ya estaba, ya hay una conciencia lúcida (desde el alba ya se está"con los ojos abiertos"). Este dístico se repite siete veces en la novela, dando lugar, cada vez, a una nueva secuencia que narra, obsesivamente, el mismo día, un día inaugural puesto que es el relato de un primero de enero. Una apoteosis de un comienzo que no pasa, que se 
repite ; una focalización aguda en ese instante en que surge el relato y el tiempo. En la novela encontramos, varias veces, la misma dinámica de anulación del relato en una nada originaria y una progresiva reconstrucción de la literatura a partir de ella. En particular, leemos en un momento dado una cosmogonía, una parodia del Génesis situado en la zona ; es el relato de la creación de las islas, del mundo, del hombre, de la sociedad y, por fin, del escritor : el Génesis burlón de la obra de Saer.

Otro ejemplo. El entenado retoma y amplía estos relatos fundacionales (ya había un esbozo de ellos en la primera novela escrita, La vuelta completa), haciendo de la fundación de la zona (la historia de los colastiné, primeros habitantes de la"ciudad", y del protagonista, primer hispanohablante y primer"inmigrante" en esas tierras que serán alguna vez Argentina), un relato de pérdida y recuperación de la lengua y la cultura, o sea, un relato de iniciación a la escritura. La historia narrada supone una"vuelta", un viaje de España a la zona que toma visos de una regresión cósmica, de vuelta y al espacio mítico del origen. Años después y a modo de autointerpretación, en El río sin orillas, Saer compara al Río de la Plata a un sexo masculino penetrando el cuerpo femenino de América del Sur, lo que haría, siguiendo una anatomía muy aproximativa pero imaginariamente significativa, de la zona, de Santa Fe, el lugar del seno materno, del origen de la vida.

A esta enumeración habría que agregar, por supuesto, estudios sobre los mecanismos de escritura, y muy particularmente sobre la relación de Saer con los incipits, o con las prácticas de anotación, traducción y comentarios de lectura que acompañaba su tarea creadora, todo lo cual es, hoy, bastante conocido gracias al estudio que pudimos realizar sobre el dossier genético de Glosa y El entenado (publicado en la edición Archivos de esas dos novelas) y por el trabajo que estamos realizando sobre el fondo legado por el escritor. Algunas primeras conclusiones al respecto fueron presentadas en el coloquio parisino Juan José Saer. Archivos, memoria, crítica, y publicadas en otro número de Cuadernos LIRICO. Parte de ese material está en vías de publicación en Seix Barral, Argentina, bajo el título genérico de Papeles de trabajo. Borradores inéditos. ${ }^{15}$

Dejando de lado los ejemplos y retomando una reflexión de tonalidad general. El origen es, dijimos, a la vez un espacio y un tiempo pasado. El origen es una ciudad y una región, obsesivamente representadas y al mismo tiempo el terreno para acumular todas las incertidumbres e imposibilidades que cualquier representación presupone. Ese"lugar de origen" es, por lo tanto, el epítome de lo real, pero es también una cifra de lo perdido, ese tiempo antes del tiempo en la que el sujeto nace y se determina en tanto que conciencia plena. El origen es un momento del pasado, siempre más allá de la historicidad humana, que a la vez está fuera de alcance y que podría explicar o determinar el sentido del sujeto y del presente. Así, en la obra de Saer, no sólo se vuelve, una y otra vez, a la representación problemática de esa ciudad cualquiera y ese paisaje sin relieve que la rodea, sino que también se intenta, una y otra vez, recuperar el pasado, narrar lo sucedido, probar que, algún día y de alguna manera, se podrá negar el tiempo ineluctable que nos separa imaginariamente del origen. Narrar es poner en escena un espacio y un tiempo de origen, a la vez anhelado e inalcanzable. Se narra desde el después y desde el afuera, para contar un doble movimiento : la literatura ya está, siempre, empezada y la literatura no puede sino volver a ese comienzo, a las circunstancias del origen : el origen es, entonces, el objetivo en sí de la literatura. ${ }^{16} \mathrm{En}$ esta perspectiva, la obra retoma modos de pensar el origen que fueron surgiendo en los mismos años en que ésta se escribía (a partir de los sesenta), en particular el postulado 
que vivimos siempre en el después, en el más allá del origen. Al origen siempre se lo observa, convoca e interpreta desde una posteridad nostálgica o exigente. El origen es lo perdido, lo faltante, lo que imaginariamente podría proponernos una plenitud que sabemos inverosímil. ${ }^{17}$

Porque la manera saeriana de focalizarse en un origen, que resulta en varios niveles paradójica, se inscribe no sólo en una filiación borgeana, sino también en lo podría llamarse un"paradigma moderno del origen", es decir en una redefinición reciente de la idea de origen y de los relatos que lo significan y transmiten, redefinición en la cual el nombre de Foucault resulta central, tal cual pudimos verlo al comienzo de esta introducción. Siguiendo a Benjamin para leer a Saer podríamos afirmar entonces que :"El origen es un torbellino en el río del devenir, y arrastra en su ritmo la materia que está apareciendo."18

Más precisamente, las lecturas propuestas también permiten cristalizar otras ideas, frecuentes en la bibliografía sobre el tema : el origen no es un absoluto sino un relato, una construcción. Ficticio y convencional, el origen es operativo a pesar de su relatividad. Al origen se lo fabrica. ${ }^{19}$ Es desde el después que la mirada retrospectiva reconstruye el modelo ideal, ese Génesis o Big-bang semántico, y al hacerlo, al recorrer el camino de una repetición y de una regresión, se va constituyendo una cadena causal y un sistema de determinaciones que surgen después de sus efectos supuestos (característica que el origen compartiría con el relato biográfico en tanto que relato explicativo del devenir de un sujeto). Una y mil veces se puede, por lo tanto, volver a narrar el principio del mundo y de la obra, como lo hace Saer, proponiendo nuevas variantes y construcciones diferentes, sin cerrar con una verdad esencial y pura el sentido del origen.

Sin embargo, el origen es, ante todo, un lugar de sentido supuesto, de sentido anhelado. El comienzo, la primera página, el primer hombre, la creación, el gesto inaugural, la fundación, son determinadores totalizantes y exclusivos de sentido. La mirada retrospectiva y la construcción de un origen son intentos por lo tanto de atribución de sentido a un sistema simbólico, a una organización social, a una obra artística, a una biografía, atribución de la que hemos aprendido a descreer. ${ }^{20} \mathrm{Al}$ final de"Algo se aproxima", encontramos una afirmación explícita de lo absurdo de la vida ("¿Qué sentido tiene la vida? [...] Ninguno, por supuesto"21); toda la representación dinámica del origen en Saer parte de ese desencanto e intenta reemplazar el sentido que tendría que encontrarse en el origen por un movimiento de búsqueda, a la vez fértil e inútil.

Lo dicho traza por lo tanto el mapa de la originalidad saeriana, en el sentido de su posición ante la negatividad moderna, que el acto del comienzo cristaliza. Por un lado, escribir será escribir una imposibilidad de escribir o sea escribir a partir de ella. No pretender resolverla ni superarla sino, diría Saer, hundiéndose en esa dificultad, en la"complejidad" de esa situación. Por lo tanto, escribir la pérdida, la desconfianza ante el sentido, el desconcierto ante el mundo y lo convencional de cualquier comienzo. Escribir desde una postura melancólica. Respuesta, ésta, que no es ajena, a pesar de inmensas diferencias, a la de Borges. Pero, también, como pudimos verlo en algunas afirmaciones precedentes, escribir -seguir escribiendo- es empezar de cero, es construir un comienzo propio, narrar la propia prehistoria, definiendo un lugar, un tiempo, un universo, una genealogía, una ficción de inicios. Empezar escribiendo obsesivamente el comienzo, tematizándolo, situándolo en el centro de la producción rechazando por lo tanto una ligazón genética con padres literarios o con una historia 
de las letras precedente-. O sea : a la vez escribir la imposibilidad e, imaginariamente, escribir un grado cero, un primer día, un universo íntimo. Vimos que, paradójicamente, esta otra vertiente es, también, operativa en el caso de Borges. Pero ampliando la analogía y jugando con las simetrías : podríamos comparar esta actitud con Onetti (o con las estrategias de Onetti frente a un Faulkner venerado y antecesor en todo lo escribible), que no se sitúa, como diría Said, en una continuación dinástica de Faulkner (como su heredero), sino en una contigüidad. ${ }^{22}$ Onetti reproduce algunos gestos mayores, instalando su propio espacio, Santa María, como un terreno fronterizo y por lo tanto paralelo al condado estadounidense. En esa geografía o filiación horizontal se funda también la zona saeriana.

El eterno comenzar de lo ya comenzado que fabula Saer, es una manera de hacer funcionar al origen como horizonte, posibilidad, quimera. El origen no es el espacio en sí ni el momento de la emergencia, sino la mirada retrospectiva que se tiende hacia ellos, las imágenes y recuerdos que, disímiles y confusos, se construyen a partir de ellos, los valores de certeza o de duda que se pretende percibir en ellos. 0 , más bien, el origen es ese desplazamiento que a la vez vuelve, esboza formas en las tinieblas de lo perdido e intenta, vanamente, nombrar y determinar el pasado. El origen es la pérdida pero es también el retorno. El origen es ese movimiento, en el espacio y en la cultura, en la memoria y en el lenguaje, en los sueños y en las fantasías, que deja de avanzar y busca volver, retomar pie en lo que no es, en lo que se va inventando a medida que uno se acerca. Borges termina su"Arte poética" con una imagen legendaria :"Cuentan que Ulises, harto de prodigios, / lloró de amor al divisar su Itaca / verde y humilde." Y en el poema"Itaca", Kavafis recuerda :"Cuando salgas de viaje para Ítaca, / desea que el camino sea largo, / colmado de aventuras, de experiencias colmado." El origen sería, también, lo que no está más cuando Ulises, harto de prodigios, llega por fin; el origen no es Ítaca sino esa verde eternidad, más allá de cualquier lugar, circunstancia o peripecia, ante la cual el heroico viajero estalla en llanto. El origen no sería sino ese camino largo, esa búsqueda inútil, esa confrontación decepcionante, y todo lo que se trae consigo : las experiencias, las aventuras, la sabiduría. O sea, podría verse el origen como eso a lo cual no se puede retornar, no porque tal o cual retorno sea un fracaso o una paradoja, sino porque el origen sólo puede materializarse, percibirse, decirse en esa decepción, en esa confrontación con lo que no está. El dibujo, la trama, la delimitación de lo ausente, de lo ausente que, sin embargo, nunca existió : ése sería el origen para el viajero que vuelve. El origen como un horizonte verde, eterno y vacío, hacia el que se regresa luego de un largo viaje, lo que también podría ser, por supuesto, una imagen del final, una imagen de la muerte.

\section{BIBLIOGRAFÍA}

AGAMBEN, Giorgio, Singatura rerum. Sur la méthode, París : Vrin, 2008.

ADORNO, Theodor. W., Théorie esthétique, París, Klincksieck, 1995.

ARENDT, Hannah, La crise de la culture : huit exercices de pensée politique, París : Gallimard, 2000. 
BARTHES, Roland, La préparation au roman I et II, París : Seuil, 2003.

BENJAMIN, Walter, Orígenes del drama barroco alemán, París : Flammarion, 1985.

BOIE, Bernhild y FERRER, Daniel (eds.), Genèses du roman contemporain : incipit et entrée en écriture, París : CNRS Ed., 1993.

BOURDIEU, Pierre,"L'illusion biographique" in Raisons partiques. Sur la théorie de l'action, París : Seuil, 1994, p. 81-90.

CALVINO, Italo,"Commencer et finir" en Defis aux labyrinthes II. Textes et lectures critiques, París : Seuil, 2003, p. 105-121.

DERRIDA, Jacques, Mal d'Archive, París : Galilée, 1995.

DI CIO, Mariana y LITVAN, Valentina (eds.), Juan José Saer. Archivos, memoria, crítica, Cuadernos LIRICO ${ }^{\circ} 6$, diciembre 2011.

F.A. (Le fait de l'analyse) n 10, printemps 2001, La fabrication de l'origine, París : Autrement.

FOUCAULT, Michel,"Nietzsche, la généalogie, l'histoire", en Dits et écrits. Volume I 1954-1975, París : Gallimard, p. 1004-1025.

FOUCAULT, Michel, L'ordre du discours, París : Gallimard, 1971.

FOUCAULT, Michel, Las palabras y las cosas, México : Siglo XXI, 1989.

FOUCAULT, Michel, L'archéologie du savoir, París : Gallimard, 2008.

FREUD, Sigmund, Totem et tabú, en Obras completas V, Madrid : Biblioteca Nueva, 1972,

p. $1745-1850$.

GRAMUGLIO, María Teresa,"El lugar de Saer", en Juan José Saer por Juan José Saer, Buenos Aires : Celtia, 1986, p. 261-300.

GRESILLON Almuth, Eléments de critique génétique. Lire les manuscrits modernes, París : PUF, 1994.

HAY Louis, (ed.) La naissance du texte, París : J. Corti, 1989.

HAY Louis, La littérature des écrivains. Questions de critique génétique, París : José Corti, 2002.

HERSCHBERG-PIERROT Anne, Le style en mouvement. Littérature et art, París : Belin sup, 2005.

HOBSBAWM, Eric y RANGER, Terence, L'invention de la tradition, París : Éditions Amsterdam, 2006.

KERMODE Franz, El sentido de un final, Barcelona, Gedisa, 2000.

LAPLANCHE, J. y PONTALIS, J.-B., Fantasme originaire. Fantasmes des origines. Origines du fantasme, París : Hachette, 1985.

LOIS Elida, Génesis de escritura y estudios culturales. Introducción a la crítica genética, Buenos Aires : Edicial, 2001.

LUNGO, Andrea del, L’incipit romanesque, París : Éditions du Seuil, coll."Poétique", 2003.

MAN, Paul de,"Génesis y genealogía (Nietzsche)", en Alegorías de la lectura, Barcelona : Lumen, 1990, p. 100-126.

MILNER, Jean-Claude, L'oeuvre claire. Lacan, la science, la philosophie, París : Seuil, 1995.

PREMAT, Julio,"En la zona : estando empezando", en P. Ricci (ed.), Prólogos a la obra de Saer, Santa Fe : UNL-Seix Barral, 2011, p. 19-35.

ROBERT, Marthe, Roman des origines, origines du roman, París : Grasset, 1972. 
SAER Juan José, Cuentos completos, Buenos Aires : Seix Barral, 2001.

SAER Juan José, Glosa - El entenado, edición coordinada por J. Premat, Poitiers-Córdoba : Alción, 2010.

SAER Juan José, Papeles de trabajo 1. Borradores inéditos, Buenos Aires : Seix Barral, 2012.

SAID Edward, Beginnings. Intention \& method, New York : Columbia University Press, 1985.

SAID Edward, El mundo, el texto y el crítico, Buenos Aires : Debate, 2004.

SIBONY, Daniel, Entre-deux : l'origine en partage, París : Seuil, 1991.

STAROBINSKI, Jean,"La perfection, le chemin, l'obstacle"en Starobinski en mouvement, bajo la dirección de Murielle Gagnebin y Christine Savinel, Seyssel : Champ Vallon, 2001, p. 471-492.

\section{NOTAS}

1. G. Agamben, Singatura rerum. Sur la méthode, París : Vrin, 2008, p. 94.

2. M. Foucault : L'archéologie du savoir, París : Gallimard, 2008, p. 33-40.

3. Ibid., p. 15.

4. G. Agamben, op. cit., p. 103.

5. M. Foucault,"Nietzsche, la généalogie, l'histoire", en Dits et écrits. Volume I 1954-1975, París : Gallimard, p. 1004-1005.

6. Ibid., 1006-1007.

7. L. Hay, La littérature des écrivains. Questions de critique génétique, París : José Corti, 2002, p. 247, subrayado mío.

8. J.-C. Milner, L'oeuvre claire. Lacan, la science, la philosophie, París : Seuil, 1995, p. 14-15.

9. Op. cit., p. 14. Sobre lo inacabado, ver A. Herschberg-Pierrot, Le style en mouvement. Littérature et art, París : Belin sup, 2005, p. 113-140.

10. La littérature des écrivains, op. cit., p. 7-30.

11. Juego de palabras obviamente intraducible, que asocia publicación (publication) con la basura (en este caso, el tacho de basura : la poubelle).

12. J. Derrida, Mal d'Archive, París : Galilée, 1995, p. 11.

13. E. Saïd, Beginnings. Intention \& method, New York : Columbia University Press, 1985, p. 5.

14. Sobre el valor de En la zona en tanto que comienzos de la producción saeriana, véase : M. T. Gramuglio :"El lugar de Saer", en Juan José Saer por Juan José Saer, Buenos Aires: Celtia, 1986, p. 261-300 y mi artículo,"En la zona: estando empezando", en P. Ricci (ed.), Prólogos a la obra de Saer, Santa Fe : UNL-Seix Barral, 2011, p. 19-35.

15. J. Premat, D. Vecchio, G. Villanueva,"Un arte de escribir. los manuscritos de Glosa y El entenado", en J. J. Saer, Glosa - El entenado, edición coordinada por J. Premat, Poitiers-Córdoba : Alción, 2010, p.475-579; G. Villanueva,"Un narrador sobre el caballo de la calesita. Estudio genético de los incipits y los excipits en la narrativa de Juan José Saer", en M. Di Ció y V. Litvan (eds.), Juan José Saer. Archivos, memoria, crítica, Cuadernos LIRICO n 6, p. 93-114, consultable en revue.org; J. J. Saer, Papeles de trabajo 1. Borradores inéditos, Buenos Aires : Seix Barral, 2012.

16. Por lo tanto, el comienzo puede ser un objetivo :"[...] belonging as often to myth as to logic, conceived of as place in time, and treated as a root as well as an objective, remains a kind of gift inside language". E. Said, Beginnings. Intention \& method, New York: Columbia University Press, 1985 , p. 43.

17. Foucault afirma al respecto, en Las palabras y las cosas que el hombre"se descubre ligado a una historicidad ya hecha : nunca es contemporáneo de este origen que se esboza a través del tiempo 
de las cosas sustrayéndose a él [...] El hombre siempre puede pensar lo que para él es válido como origen sólo sobre un fondo de algo ya iniciado." México : Siglo XXI, 1989, p. 321.

18. W. Benjamin, Orígenes del drama barroco alemán, París : Flammarion, 1985, p. 56. Traducción mía.

19. Ver F.A. (Le fait de l'analyse) $n^{\circ} 10$, printemps 2001, La fabrique de l'origine, París : Autrement.

20. Finalmente, el valor de lo que Franz Kermode llama"tipos apocalípticos" funciona de manera similar ("los tipos apocalípticos -imperio, decadencia y renovación, progreso y catástrofe- se nutren de la historia y son la base de nuestras maneras y de hallar sentido al mundo, desde el punto que ocupamos, el mismo medio", F. Kermode, El sentido de un final, Barcelona, Gedisa, 2000, p. 37).

21. J. J .Saer, Cuentos completos, Buenos Aires : Seix Barral, 2001, p. 536.

22. E. Saïd, El mundo, el texto y el crítico, Buenos Aires : Debate, 2004, p. 32.

\section{AUTOR}

\section{JULIO PREMAT}

Université París 8 Vincennes - Saint-Denis 